\title{
Phenotypic and genotypic characteristics of exopolysaccharide- producing fungi as a source of food additives
}

\author{
ROBBY AKROMAN ${ }^{1}$, NURHAYATI NURHAYATI ${ }^{2,3}$, SONY SUWASONO ${ }^{3}$, JAY JAYUS ${ }^{3,4, \boldsymbol{v}}$ \\ ${ }^{1}$ Graduate School of Biotechnology, Universitas Jember. Jl. Kalimantan No. 37, Jember 68121, East Java, Indonesia. \\ ${ }^{2}$ Center for Development of Advanced Sciences and Technology, Universitas Jember. Jl. Kalimantan No. 37, Jember 68121, East Java, Indonesia \\ ${ }^{3}$ Department of Agricultural Products Technology, Faculty of Agricultural Technology, Universitas Jember. J1. Kalimantan No. 37, Jember 68121, East \\ Java, Indonesia. Tel.: +62-331-321784. `email: jayus.ftp@unej.ac.id, akromanrobby23@gmail.com \\ ${ }^{4}$ Center of Excellent for Industrial Plant Biotechnology, Universitas Jember. Jl. Kalimantan No. 37, Jember 68121, East Java, Indonesia
}

Manuscript received: 2 May 2019. Revision accepted: 12 August 2019.

\begin{abstract}
Akroman R, Nurhayati N, Suwasono S, Jayus J. 2019. Phenotypic and genotypic characteristics of exopolysaccharideproducing fungi as a source of food additives. Biodiversitas 20:2468-2474. As the demand for materials suitable for edible film in food processing is increasing, the exploration of exopolysaccharide (EPS) producing fungi is important. Some fungi had been reported to produce extracellular polysaccharide having rheological properties potential as thickener and or plasticizer useful for edible film raw material. Therefore, this study was focused on isolation and identification of EPS-producing fungi from the plantation area surrounding the University of Jember, Indonesia. The fungal isolate obtained was morphologically identified based on mycelia and spore type, while its genotype was determined using ITS1 and ITS4 primers. The optimum initial culture $\mathrm{pH}$ for EPS production was measured using shake flask culture fermentation. The rheological properties of the EPS were determined using Brookfield viscometer, and surface structure of EPS was observed using a scanning electron microscope (SEM). The result showed that the mycelium of the isolate was reddish-brown and septated, its spores were formed as conidiospores. Internal Transcribed Spacer (ITS) sequence of the fungus showed that the isolate is a new species. Therefore, it was designated as $C$. lunata isolate RJ01. Optimum initial $\mathrm{pH}$ for EPS production was $\mathrm{pH}$ 6.0, achieved after 5 days fermentation yielded $2.6 \mathrm{~g} \mathrm{~L}^{-1}$ of EPS. The EPS from $C$. lunata isolate RJ01 have no cytotoxic activity on vero cell. The rheological behavior of $C$. lunata EPS was viscous, and its surface structure of EPS was compact indicating its potency as thickening agent and plasticizer, a material required for edible film formation in food industries.
\end{abstract}

Keywords: Culvularia lunata, exopolysaccharide, genotypic, phenotypic

\section{INTRODUCTION}

Over the last two decades, the demand for film materials for food packaging is increasing (Ramos et al. 2013) to fulfill the industrial need. However, most packaging materials available are considered as a nonrenewable and non-biodegradable, and of course nonenvironmentally friendly, because it will consequently be the main source of solid waste and environmental pollutant (Parreidt et al. 2018). Effort to solve this problem is, among others, through the application of edible film which is abundantly available as the packaging material made from renewable natural polymers (Gontard and Guilbert. 1994). This includes exopolysaccharide from microorganism (Rodriguez et al. 2017), especially fungi. Some fungi had been reported to have the ability to excrete such materials in high amount (Liu et al. 2016).

As one of the EPS sources (Mahapatra and Banerjee 2012), fungi are currently attractive because they are rich in various biologically active substances (Nehad and Shamy 2010). The exopolysaccharides they secreted have several functions as emulsifiers, stabilizers, film making, viscosifying and gelling agents (Mathur and Mathur 2006; Patel et al. 2014). Some fungal EPS exhibit a rheological property showing a pseudoplastic non-Newtonian behavior, and also non-porous compact surface; potential as plasticizer for making edible film making. Hence, it has potential application as packaging material (Sajna et al. 2013).

Some fungi have been reported to be able to produce EPS, which are potential as food additives such as Sporobolomyces salmonicolor AL1 as thickener or gelatinizer (Pavlova et al. 2004) and Rizobium tropici LBMP-C01 as emulsifier (Moretto et al. 2015). However, the EPS yield of those fungi were varied without any clear relationship between the yield and the type of fungal strain (Mahapatra and Banerjee 2012). The physical properties of those EPS were also different depending on the structure of the EPS produced. Therefore, exploration of fungal strain producing high EPS yield is essential. The present study aimed to isolate, and to phenotypically and genotypically identify EPS-producing fungi from the plantation area surrounding the University of Jember (UNEJ), East Java, Indonesia, and the potency of the EPS as a source of edible film.

\section{MATERIALS AND METHODS}

\section{Media for isolation of fungi}

Media for isolation of the fungi were malt extract agar (MEA; Merck). These media were used to capture and 
screen the fungi from the plantation area. Czapek dox broth (oxoid) was used as the carbon source for EPS production. Mineral salts solution was formulated according to the method of Pitson et al. (1991) and modified by Jayus et al. (2002) using $\mathrm{K}_{2} \mathrm{HPO}_{4}$ (oxoid) and $\mathrm{Na}_{2} \mathrm{HPO}_{4}$ (oxoid) to optimize the isolate's growth in the czapek dox liquid medium.

\section{Isolation of EPS-producing fungi}

The EPS-producing fungi were isolated using the method of Schmid et al. (2001). The sterile MEA was prepared in a Petri dish, placed on the plantation area surrounding the UNEJ for 5 minutes at several points of locations. The medium was then incubated at $28^{\circ} \mathrm{C}$ for three days, followed by the screening of all the captured strain to obtain some single isolates. Isolation of pure isolate was carried out at the Laboratory of Centre for Development of Advanced Science and Technology (CDAST), the University of Jember, Indonesia. The fungal isolates obtained were then stored on a sterile soil at $4^{\circ} \mathrm{C}$.

\section{Phenotypic identification of EPS-producing fungi}

The characteristics of mycelia, conidiophores, and conidia were observed using the Riddle and Briggs method (1950). The color of the isolate was observed as described in Methuen handbook of color (Kornerup and Wanscher 1967). The slide culture was prepared according to the protocol described by Kumar et al. (2012) and Astriani et al. (2018). The fungal microscopic features were observed under XSZ-107 binoculars microscope at 400x magnification. One loop of mycelia was inoculated into a sterile droplet of MEA on a preparation glass and incubated at $28^{\circ} \mathrm{C}$ for four days. The isolate morphology was previously identified (Sumangala et al. 2010; Manamgoda et al. 2012; Marin-Felix et al. 2017; Heidari et al. 2018).

\section{DNA isolation, PCR amplification, and sequencing}

Genomic DNA of the fungal isolate was extracted using the ZR Fungal/Bacterial DNA Kit ${ }^{\mathrm{TM}}$ and subjected to PCR amplification using ITS1 and ITS4 primers (Barus and Steffysia 2013). The PCR reaction mixture was in a total volume of $25 \mu \mathrm{L}$ containing dd $\mathrm{H} 2 \mathrm{O}(5 \mu \mathrm{L})$, DNA template $(1 \mu \mathrm{L})$, ITS 1 and ITS4 primers $(0.5 \mu \mathrm{L}$ each), PCR buffer KOD FX neo $(12.5 \mu \mathrm{L}), 2 \mathrm{mM}$ dNTPs $(5 \mu \mathrm{L})$, and KOD FX neo (0.5 units). PCR conditions were: 1 cycle of $3 \mathrm{~min}$ initial denaturation at $95^{\circ} \mathrm{C}$, followed by 35 cycles of 10 sec denaturation at $98^{\circ} \mathrm{C}, 30 \mathrm{sec}$ primer annealing at $52^{\circ} \mathrm{C}$, $45 \mathrm{sec}$ extension at $68^{\circ} \mathrm{C}$, and a cycle of final extension period at $72^{\circ} \mathrm{C}$. The PCR product was then separated on an agarose gel $(2 \% \mathrm{w} / \mathrm{v})$, stained with ethidium bromide, and visualized under UV light using Chemdoc Gel System (Bio-Rad). The amplified PCR product was then sequenced using bi-directional sequencing. The isolate RJ01 was identified by comparing its nucleotide sequences against the Gene Bank database using BLAST (Basic Alignment Search Tools) and a phylogenetic tree was constructed using neighbor-joining at MEGA 5.05 software (Oslan et al. 2012).

\section{Production of exopolysaccharide}

Exopolysaccharide production was carried out under different initial culture $\mathrm{pH}(4,5,6,7,8)$ of its fermentation. The mycelium of each of the isolates was inoculated into czapek dox broth medium in 1 L Erlenmeyer flask and incubated in a shaking incubator at $28^{\circ} \mathrm{C}$ for 6 days (Schmid et al. 2001). Samples were observed every $24 \mathrm{~h}$ interval for the biomass and the yield of EPS. Biomass was removed by centrifugation, and the EPS in the supernatant was precipitated using ethanol $(96 \%)$ and then centrifuged at $5000 \mathrm{rpm}$ for 5 minutes (Ramirez 2016). The EPS was then dialyzed for 24 hours against water to remove any remaining low molecular weight compounds, and freezedried using a Virtis Advantage Plus freeze-dryer (SP scientific, Warminster, USA). EPS assay were performed using crude $\beta$-glucanases obtained from culture media of Acremonium sp. IMI 383068 grown on pustulant as substrate, as described by Jayus et al. (2001 and 2004). The EPS $(2 \mathrm{mg} / \mathrm{mL})$ were hydrolyzed by the enzyme in sodium acetate buffer $(50 \mathrm{mM} \mathrm{pH} \mathrm{5.0)}$ containing the EPS as a substrate at $40^{\circ} \mathrm{C}$ for $30 \mathrm{~min}$. Reducing sugars released were measured using DNS method of Miller (1959).

\section{Viscosity analysis of EPS}

Viscosity of the EPS was analyzed using Brookfield DV-II+ Pro with an SC4-18 spindle at room temperature. Its viscosities were measured under a range of concentration between 0.25 to $1.5 \%$.

\section{Scanning electron microscopic analysis of the EPS}

Surface microstructure analysis was performed using a Tabletop Scanning Electron Microscope TM303plus (Hitachi High Technologies Corporation, Japan) at the Pharmaceutical Laboratory, Faculty of Pharmacy, University of Jember, Indonesia. The EPS in the form of fine dry powder was observed under a low vacuum environment at the acceleration voltage of $5.0 \mathrm{kV}$.

\section{Cytotoxicity analysis of EPS}

Cytotoxicity of EPS was observed using normal vero cells and EPS concentrations of $15.625 ; 31.25 ; 62.5 ; 125$; $250 ; 500 ; 1000 \mu \mathrm{g} \mathrm{mL}^{-1}$. The vero cells (5 x 104 cells) were inoculated first into 96 multi-well plates filled with M199 medium (Permanasari et al. 2016) and Hanks'salt solution (Sigma M9163) $(100 \mu \mathrm{L})$. Then, the plates were incubated at $37^{\circ} \mathrm{C}$ in $\mathrm{CO}_{2}(5 \%)$ incubator for 24 hours until cells had attached to the well wall. The aliquots of EPS sample of the different concentrations were then added $(100 \mu \mathrm{L})$, and the wells were incubated for another 24 hours. To measure cell viability, proliferation, and activation, 3- (4, 5-dimethyl thiazolyl-2)-2 and 5-diphenyltetrazolium bromide (MTT) $(100 \mu \mathrm{L})$ were added and further incubated for 2-4 hours at room temperature. SDS $(10 \%, 100 \mu \mathrm{L})$ in $\mathrm{HCl}(0,01 \mathrm{~N})$ was then added to stop growth of vero cell. Plates were wrapped in aluminum foil and incubated in the dark overnight. An ELISA plate reader, set at $595 \mathrm{~nm}$ wavelength, was used to measure the cell viability by comparing the absorbance of sample wells to the control wells. 


\section{Statistical analysis}

The replicated data were expressed as mean \pm SD (standard deviation). Analysis of cytotoxicity data was carried out using SPSS 17.0, where the $\mathrm{P}$ values were determined by one-way ANOVA, followed by the Tukey test.

\section{RESULTS AND DISCUSSION}

\section{EPS-producing fungi isolated from the plantation area of UNEJ surrounding}

The unscreened fungal colony captured by MEA on the plate appeared colorful as can be seen in Figure 1. Twentyfive single fungal colony were obtained from the screening process of several plates collected from several locations in the agriculture plantation area surrounding the University of Jember, Indonesia. When grown on czapek dox broth for 6 days, one of the single isolates tested was producing an exopolysaccharide, a mucus-like material termed as exopolysaccharide (EPS), secreted into the culture medium, as shown in Figure 2. The hydrolysis of the EPS using $\beta$ glucanases, released a non-reducing sugar, glucose, as proof that the mucus-like material is an extracellular polymer of polysaccharide.

\section{Morphological characteristics of EPS-producing fungi}

The visual appearance of the colony of the isolate was red, which subsequently turned to reddish-brown when it gets mature. The isolate formed a thin and cottony mycelium (Figure 3). The fungus had an aerial, branched, and septated mycelia, and a regular or irregular border shape (Figure 4.A). Its mycelia form a red colored conidiophore arising singly with simple or branching, septated, bent, and cell walls are thicker than the vegetative hyphae. The conidia are brown, shaped like a boat, circular at the ends, fusiform in shape with three septate, with the brightest end cells, usually bent or curved with enlarged central cells (Figure 4.B). Similar morphological characteristic of this kind of fungi which was identified as Curvularia had also been previously reported (Sumangala et al. 2010; Manamgoda et al. 2012; Marin-Felix et al. 2017; Heidari et al.2018).

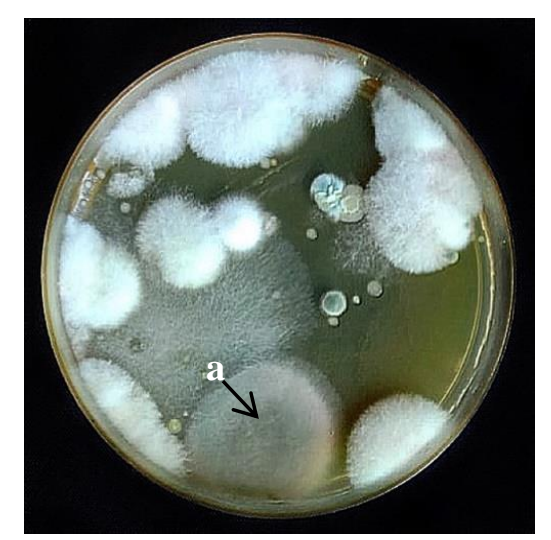

Figure 1. The appearance of captured fungi after 3 days incubation at room temperature. a. One of the potential EPS producing fungus

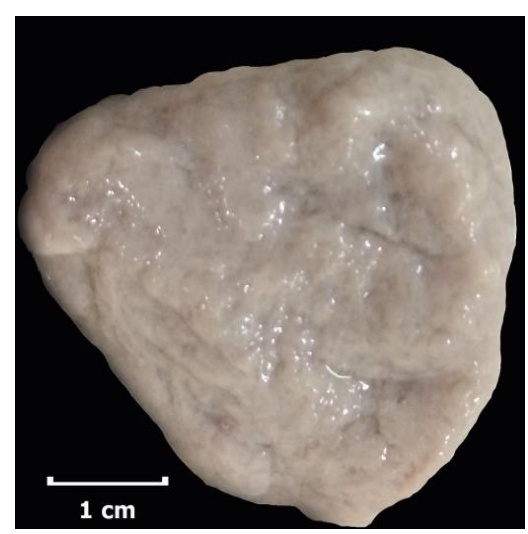

Figure 2. Exopolysaccharide appearance after being separated from the culture medium of the isolate

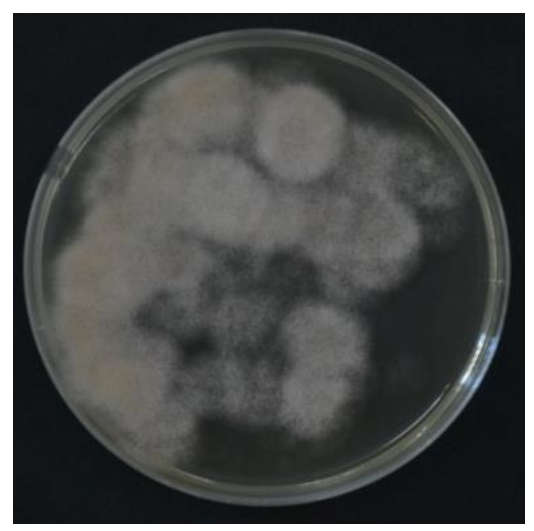

Figure 3. The single EPS-producing fungus isolated from the plantation area of surrounding the University of Jember
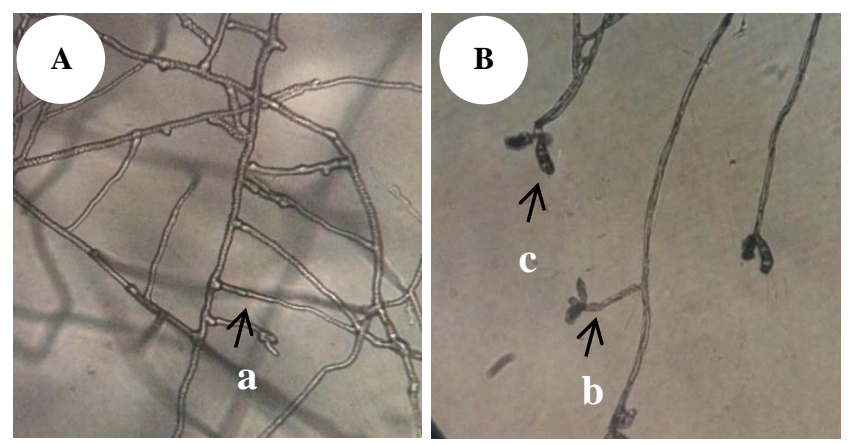

Figure 4. A-B. Morphological characteristic of the isolated EPSproducing fungus under microscopic observation at 400x magnification. Note: a. Septated hyphae, b. Conidiospore, c. Conidiospore

\section{Genotypic characteristics of EPS-producing fungi}

The PCR fragments of EPS-producing fungi was approximately 500-750 bp (Figure 5). Results of DNA sequencing of the isolate showed that the ITS region was around $565 \mathrm{bp}$. The nucleotides data of the isolate analyzed by NCBI blast tool showed the sequence similarity of the isolate of $100 \%$ quorum cover with C. lunata CY151 
(accession number: HQ607991.1) and C. lunata strains ITC19 (accession number: KY100122.1). The phylogenetic tree of all isolates shown in Figure 6 divided into three clusters (x; y; z). Cluster x contained C. aeria strain 1146 , C. lunata strain IP 2328.95, Dothideomycete sp 7644 , Cochliobolus lunatus isolate MBC002, and C. Aeria strain IP 2328.98 ISSHAM ITS isolate ID MITS1388, C. Pseudobrachyspora strain CIMAP: Ac112017, and C. lunata clone HW 001. Cluster y contained one species, namely $C$. lunata strain ITC19. Cluster z contained $C$. lunata strain CY151 and the isolated fungus.

The phylogenetic tree analysis based on ITS dataset showed that the closest relative of this isolate is $C$. lunata strain CY151 with a genetic distance of 0.004 and a unique difference of 2 nucleotides in the nucleotide number 519520. Therefore, this isolate belongs to the species $C$. lunata, which is then designated as C. lunata isolate RJ01. Full sequences of the ITS regions of $C$. lunata isolate RJ01 was deposited at the NCBI GeneBank as a new fungus under the accession number of MK629001.1.

Production of exopolysaccharide by $C$. lunata isolate RJ01

C. lunata isolate RJ01 produced an EPS during its growth on czapek dox broth media. The EPS yield increased from the third day until the fifth of incubation time (Figure 7). The highest EPS yield was obtained on the fifth day of fermentation time $\left(2.6 \mathrm{~g} \mathrm{~L}^{-1}\right)$, and this EPS yield decreased to $1.1 \mathrm{~g} \mathrm{~L}^{-1}$ on the sixth day of the cultivation time. The decrease of this yield maybe because of the substrate depletion, so the fungus may use the EPS secreted as a carbon source, a similar observation by Yi et al. (2012).

When $C$. lunata isolate RJ01 was grown under different initial $\mathrm{pH}$, the yield was varied depending on the $\mathrm{pH}$ of the culture media. Its optimum initial $\mathrm{pH}$ was 6.0 , with the highest yield of $2.6 \mathrm{~g} \mathrm{~L}^{-1}$ (Figure 8 ). This yield might be increased when this fungus grown under controlled $\mathrm{pH}$ condition during its fermentation, as has been reported by Sumangala and Patil, 2010) that Curvularia sp. was producing higher yield at $\mathrm{pH}$ 6. The optimal formation of
EPS by several other fungi such as Aspergillus ochraceous; Bionectria ochroleuca M21; and Diaporthe sp. JF766998 were achieved at pH 6-6.5 (Guo et al. 2014; Li et al. 2016; Orlandi et al. 2016). However, some fungi have been reported to have higher yield at lower $\mathrm{pH}$ values such as Antrodia camphorata with optimal exopolysaccharide at pH 5 (Shu and Lung, 2004) and Ganoderma lucidum at pH 3.5 (Papinutti, 2010).

\section{Viscosity analysis of EPS}

When the concentration of EPS in water was elevated from $0.25 \%$ to $1.0 \%$, its viscosities were increased two times from 1.01 poise to 2.23 poise, and this also higher compared to that of pullulan (1.79 poise) (Sugimoto, 1978; Tsujisaka et al. 1993) and Adansonia digitata mucilage (2.1 poise) in the same concentration of $1 \%(\mathrm{w} / \mathrm{v})$ (Deshmukh et al. 2013), indicating its high potential for use as a thickener in food industries.

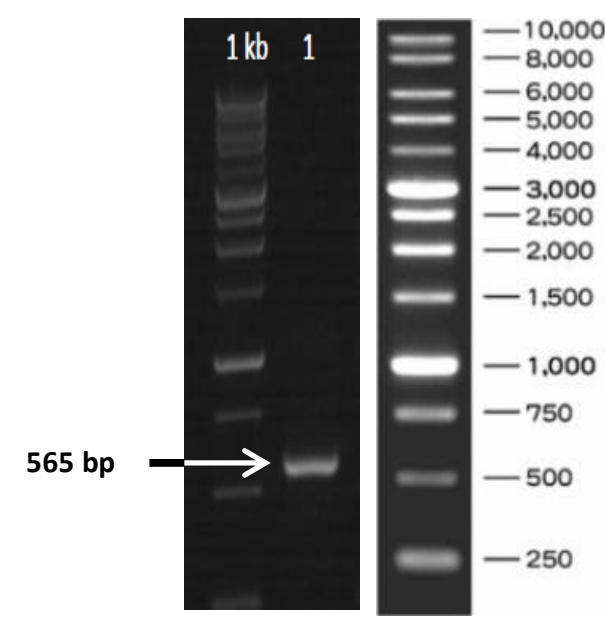

Figure 5. Electrophoresis results of $1 \mathrm{~kb}$ DNA Ladder (left), Genomic DNA band of EPS-producing fungi (middle) and $10 \mathrm{~kb}$ DNA Ladder (right).

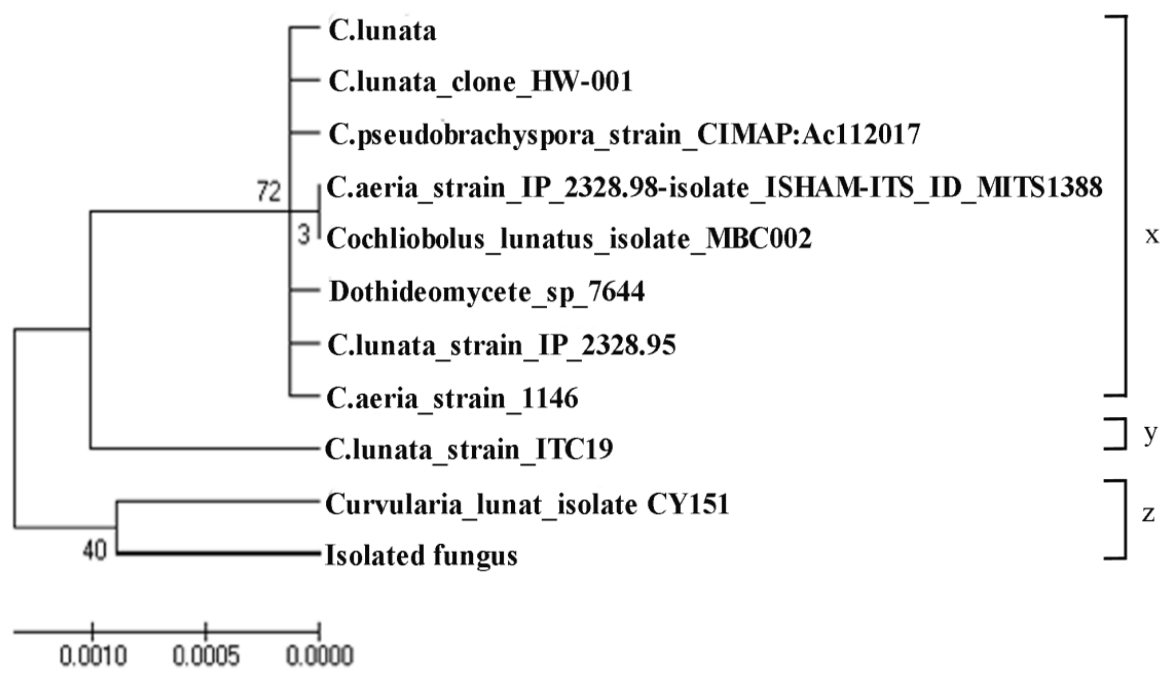

Figure 6. The phylogenetic tree of isolated fungus (C. lunata isolate RJ01) using jukes-cantor model 


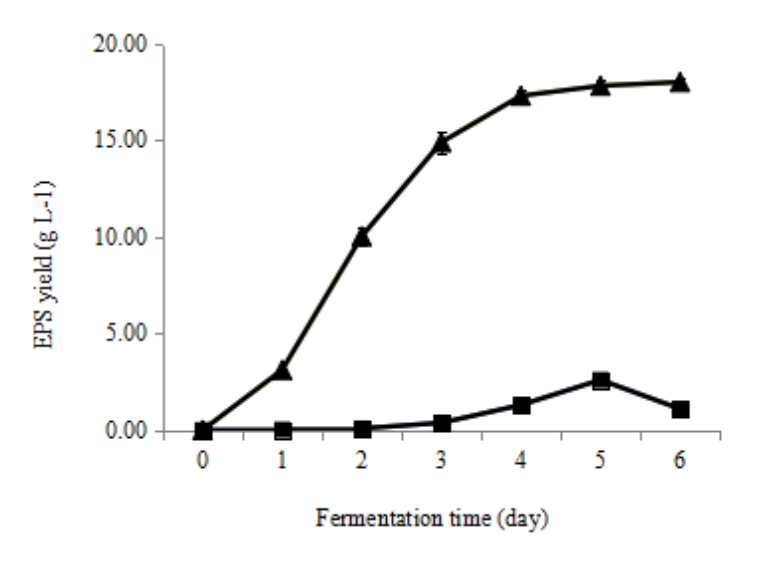

Figure 7. Yield of EPS ( $\mathbf{t}$ ) and biomass ( $\mathbf{A}$ ) of isolate RJ01 at fermentation days- 0 to days- 6

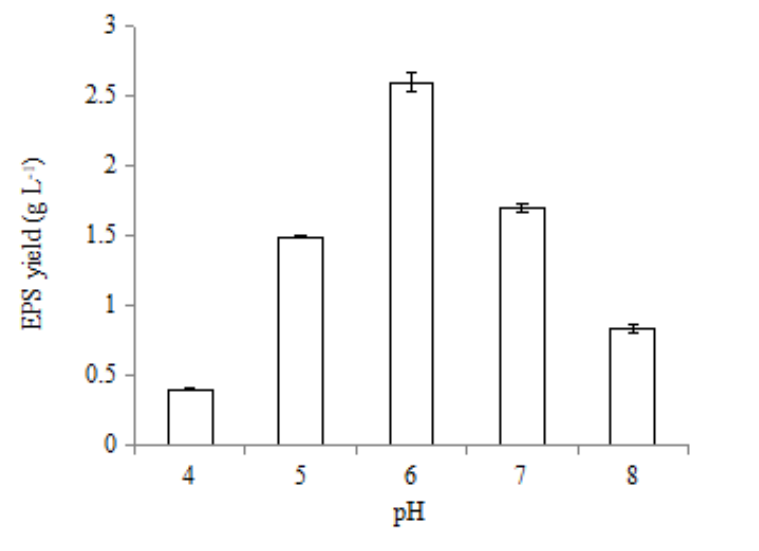

Figure 8. The effect of $\mathrm{pH}$ on the exopolysaccharide production

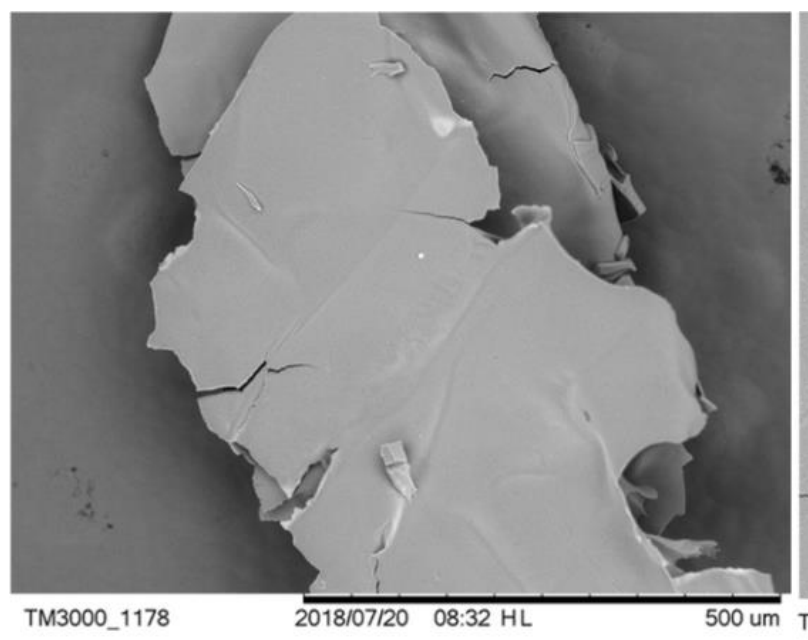

A

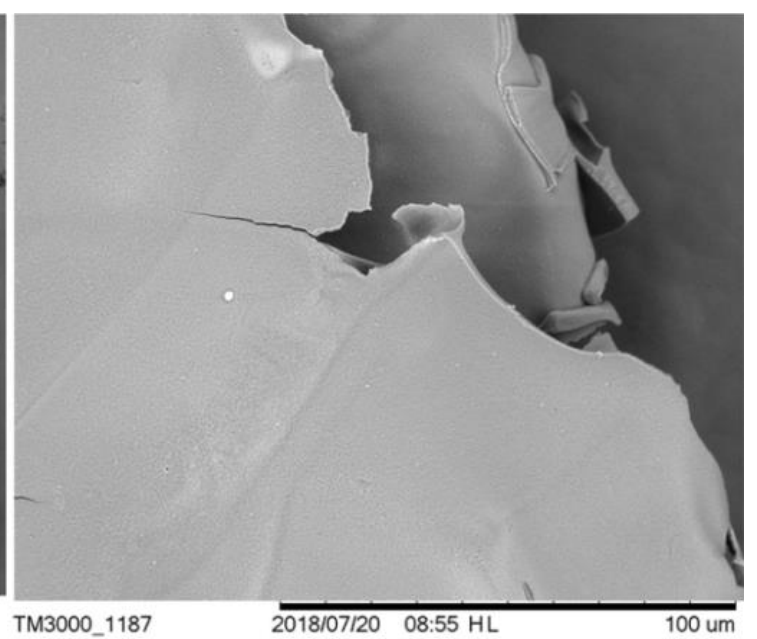

B

Figure 9. The surface morphology of C. lunata RJ01 EPS. Its compact and non-porous film-like structure on 200x (A) and 1000x (B) magnification

\section{Scanning Electron Microscopic Analysis of C. lunata isolate RJ01 EPS}

SEM analysis on the structure of EPS from $C$. lunata RJ01 showed a typical surface of non-porous film (Figure 9A) and appeared to have a compact structure (Figure 9B). Similar surface structure was reported on the EPS produced by Pseudozyma sp. NII 08165 (Sajna et al. 2013). This kind of EPS feature reflects a good potency to be used as plasticized film making materials. Exopolysaccharides are one of the potential polymers for making a bio plasticized film because of its manufacturing process is considered to be environmentally friendly and safe.

\section{Cytotoxicity of EPS of $\boldsymbol{C}$. lunata isolate RJ01}

By comparing the growth of vero cells in EPS solution with control ( $0 \%$ of EPS), there was no growth inhibition effect, even more vero cells were detected in the media containing $15.625 \mu \mathrm{g} \mathrm{mL} \mathrm{m}^{-1}$ of EPS (significant difference compared to control) (Figure 10). This indicates that the EPS from C. lunata RJ01 did not exhibit any cytotoxicity on vero cells. Likewise, in the study of $\mathrm{Li}$ et al. (2016) in Bionectria ochroleuca EPS, cell viability did not decrease significantly in normal cells treated with EPS with a concentration of $25-1600 \mu \mathrm{g} \mathrm{mL} \mathrm{m}^{-1}$. 


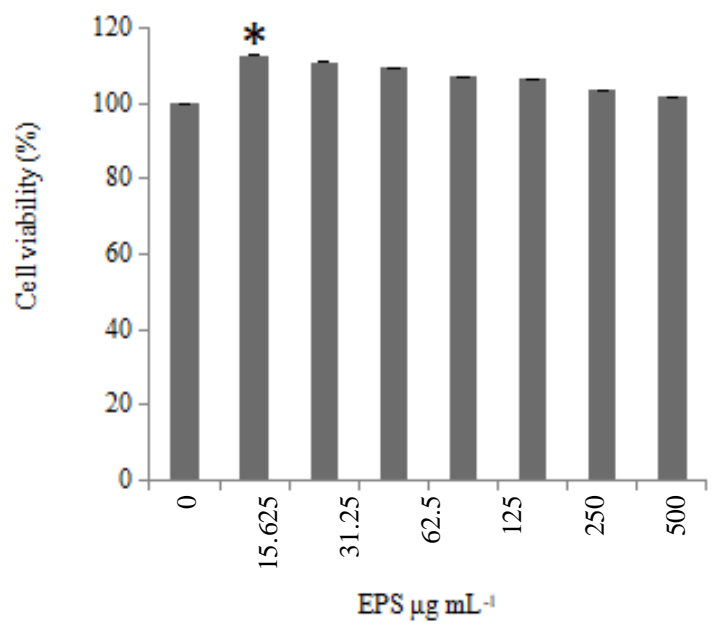

Figure 10. Cytotoxicity effect of exopolysaccharide on vero cells. $0=$ control (without EPS). Concentration chart marked $(*)$ shows significant difference $(\mathrm{P}<0.05)$ of vero cells growth compared to control.

In summary, we have isolated and identified $C$. lunata isolate RJ01 and its EPS from the agricultural plantation areas in the University of Jember. The isolate has a reddish-brown color, septate, and conidiospore. Genotypically, this isolate has the highest homology with C. lunata strain CY151, and was designated as C. lunata isolate RJ01 (accession number MK629001.1). EPS of RJ01 isolate has a non-porous compact surface suggesting its potency to be used in food industry as thickeners and plasticizer, especially on application of edible film making. Future work is needed to investigate the other functional properties of $C$. lunata isolate RJ01 EPS.

\section{ACKNOWLEDGMENTS}

The authors gratefully thank the University of Jember, Indonesia, for supporting the research fund under the scheme of IsDB Supporting Research, contract number 0713/UN25.3.1/LT/2017.

\section{REFERENCES}

Astriani A, Diniyah N, Jayus J, Nurhayati N. 2018. Phenotypic identification of indigenous fungi and lactic acid bacteria isolated from 'gatot' an Indonesian fermented food. Biodiversitas 19 (3): 947 954.

Barus T, and Steffysia. 2013. Genetic diversity of yeasts from ragi tapai" starter for cassava and glutinous rice fermentation from Indonesia" internal transcribed spacer (ITS) region. Merit Res J Food Sci Technol 1 (3): 31-35.

Deshmukh SS, Katare YS, Shyale SS, Bhujbal SS, Kadam SD, Landge DA, Shah DV, and Pawar JB. 2013. Isolation and evaluation of mucilage of Adansonia digitata Linn as a suspending agent. J Pharm $1-4$.

Gontard N, and Guilbert S. 1994. Bio-packaging: Technology and properties of edible and/or biodegradable material of agricultural origin. In: Mathlouthi M (ed.). Food Packaging and Preservation. Blackie Academic and Professional, Glasgow, UK.
Guo S, Mao W, Yan M, Zhao C, Li N, Shan J. 2014. Galactomannan with novel structure produced by the coral endophytic fungus Aspergillus ochraceus. Carbohydr Polym 105: 325-333.

Heidari K, Mehrabi-Koushki M, Farokhinejad R. 2018. Curvularia mosaddeghii sp. nov., a novel species from the family Pleosporaceae. Mycosphere 9 (4): 635-646.

Jayus, McDougall BM, Seviour RJ. 2001. Purification and properties of a $(1 \rightarrow 6)-\beta$-glucanase from Acremonium sp. IMI 383068. Enzyme Microb Technol 29: 194-200.

Jayus, McDougall BM, and Seviour RJ. 2002. Factors affecting the synthesis of $(1 \rightarrow 3)$ and $(1 \rightarrow 6)$ - $\beta$-glucanase by the fungus Acremonium sp. IMI 383068 grown in batch culture. Enzyme and Microb Technol 31: 289-299.

Jayus, McDougall BM, Seviour RJ. 2004. Purification and characterization of the $(1 \rightarrow 3)$ - $\beta$-glucanases from Acremonium sp. IMI 383068. FEMS Microbiol Letters. 230: 259-264.

Kornerup A, Wanscher JH. 1967. Methuen handbook of colour. Methuen \& Co. Ltd, London.

Kumar K, Amaresan N, Bhagat S, Madhur K, Srivastava RC. 2012. Isolation and characterization of Trichoderma spp. for antagonistic activity against root rot and foliar pathogens. Indian J Microbiol 52: 137-144.

Li Y, Guo S, Zhu H. 2016. Statistical optimization of culture medium for production of exopolysaccharide from endophytic fungus Bionectria ochroleuca and its antitumor effect in vitro. Exp Clinic Sci J 15: 211220.

Liu J, Wang X, Pu H, Liu S, Kan J, Jin C. 2016. Recent advances in endophytic exopolysaccharides: Production, structural characterization, physiological role and biological activity. Carbohydr Polym 157: 1113-1124.

Mahapatra S, Banerjee D. 2012. Structural elucidation and bioactivity of a novel exopolysaccharide from endophytic Fusarium solani SD5. Carbohydr Polym 90: 683-9.

Manamgoda DS, Cai L, McKenzie EHC, Crous PW, Madrid H. Chukeatirote E, Shivas RG, Tan YP, Hyde KD. 2012. A phylogenetic and taxonomic re-evaluation of the Bipolaris-CochliobolusCurvularia complex. Fungal Divers 56: 131-144.

Marin-Felix Y, Senwanna C, Cheewangkoon R, Crous PW. 2017. New species and records of Bipolaris and Curvularia from Thailand. Mycosphere 8: 1556-1574.

Mathur V, Mathur NK. 2006. Microbial polysaccharides based food hydrocolloid additives. Sci Tech Enterprise, UK.

Miller GL. 1959. Use of dinitrosalicylic acid reagent for determination of reducing sugar. Anal Chem 31: 426-428.

Moretto C, Castellane TCL, Lopes EM, Omori WP, Sacco LP, Lemos EGM. 2015. Chemical and rheological properties of exopolysaccharides produced by four isolates of Rhizobia. Int J Biol Macromol 81: 291-298.

Nehad EA, Shamy ARE. 2010. Physiological studies on the production of exopolysaccharide by fungi. Agric Biol J N Am 1: 1303-8.

Oslan SN, Abu BS, Raja NZRAR, Mahiran B, Adam LTC. 2012. Locally isolated yeast from Malaysia: identification, phylogenetic study and characterization. Acta Abp Biochemica Polonica 59 (2): 225-229.

Papinutti L. 2010. Effects of nutrients, $\mathrm{pH}$ and water potential on exopolysaccharides production by a fungal strain belonging to Ganoderma lucidum complex. Bioresour Technol 101: 1941-194.

Parreidt T, Müller K, Schmid, M. 2018. Alginate-based edible films and coatings for food packaging applications. Foods 7 (10): 170.

Patel M, Patel U, Gupte S. 2014. Production of exopolysaccharide (EPS) and its application by new fungal isolates SGMP1 and SGMP2. Intl J Agric Env Biotechnol 7: 511-523.

Pavlova K, Koleva L, Kratchanova M, Panchev I. 2004. Production and characterization of an exopolysaccharide by yeast. World J Microbial Biotechnol 20: 435-439.

Permanasari P, Hertiani T, Yuswanto A. 2016. Immunomodulatory effect of massoia bark extract and the cytotoxicity activity against fibroblast and vero cells in vitro. Intl J Pharm Clinic Res 8 (5): 326-330.

Pitson S, Seviour RJ, Bott J, Stasinopoulos SJ. 1991. Production and regulation of $\beta$-glucanases in Acremonium and Cephalosporium isolates. Mycol Res 95 (3): 352-356.

Ramirez MAJR. 2016. Characterization and safety evaluation of exopolysaccharide produced by Rhodotorula minute BIOTECH 2178. Intl J Food Eng 2: 31-35.

Ramos ÓL, Reinas I, Silva SI, Fernandes JC, Cerqueira MA, Pereira RN, Vicente AA, Poças MF, Pintado ME, Malcata FX. 2013. Effect of 
whey protein purity and glycerol content upon physical properties of edible films manufactured therefrom. Food Hydrocoll 30: 110-122.

Riddle OC, Briggs FN. 1950. Inheritance of resistance to scald in barley. Hilgardia 20: 19-27.

Rodriguez S, Torres FG, López D. 2017. Preparation and characterization of polysaccharide films from the Cyanobacteria nostoc commune. Polymers Renew Resour 8 (4): 133-150.

Sajna KV, Sukumaran RK, Gottumukkala LD, Jayamurthy H, Dhar KS, Pandey A. 2013. Studies on structural and physical characteristics of a novel exopolysaccharide from Pseudozyma sp. NII 08165. Int J Biol Macromol 59: 84-89.

Schmid F, Stone BA, McDougall BM, Bacic A, Martin KL, Brownlee RTC, Chai E, Seviour RJ. 2001. Structure of epiglucan, a highly side chain: branched $(1.3 ; 1.6)-\beta$-glucan from the micro fungus Epicoccum nigrum Ehrenb. ex Schlecht. Carbohydr Res 331: 163-171.
Shu CH, Lung MY. 2004. Effect of $\mathrm{pH}$ on the production and molecular weight distribution of exopolysaccharide by Antrodia camphorata in batch cultures. Process Biochem 39: 931-937.

Sugimoto K. 1978. Pullulan production and applications. J Ferment Assoc Japan 36 (2): 98-108

Sumangala K, Patil MB. 2010. Cultural and physiological studies on Curvularia lunata, a causal agent of grain discolouration in rice. Int $\mathrm{J}$ Plant Prot 3: 238-241.

Tsujisaka Y, Mitsuhashi M. 1993. Pullulan. In: "Industrial Gums (3rd Ed.) Academic Press.

Yi HA, Panepinto JC, Jacobs A. 2012. Inhibition of HIV entry by extracellular glucuronoxylomannan of Cryptococcus neoformans. Microb Pathogenesis 52: 25-30. 